\title{
A TUBERCULOSE NA CIDADE DO RIO DE JANEIRO E O TESTE DA VACINA BCG EM ESCOLARES DE ESCOLAS PÚBLICAS (1933-1935)
}

\author{
Mariza da Gama Leite de Oliveira ${ }^{1}$ \\ lattes.cnpq.br/5295891621115195
}

\begin{abstract}
Resumo: O artigo destaca os maiores desafios da Instrução Pública Primária na cidade do Rio de Janeiro no início do século XX quando era capital federal. Nesse período emergiram debates envolvendo médicos e profissionais de diversas áreas da sociedade em torno de questões educacionais e sanitárias. As principais fontes utilizadas são a revista $A$ Escola Primária e o relatório do médico Alvimar de Carvalho sobre o teste da vacina BCG, ambos do acervo da Biblioteca Nacional. Como aporte teórico, utilizam-se as possibilidades abertas pela nova história política (RÉMOND, 2003) e o auxílio da observação microscópica (GINZBURG, 1990), o que permite restaurar personagens e processos através dos indícios deixados pelos sujeitos históricos. As descobertas realizadas pelo estudo empreendido traduzem a importância do uso de fontes e de métodos variados no resgate da história das instituições escolares e sua intercessão com a história política e social.
\end{abstract}

Palavras-chave: Tuberculose, Instrução Pública Primária do Rio de Janeiro, Alvimar de Carvalho, Instituto Ferreira Vianna, Revista A Escola Primária.

\section{TUBERCULOSIS IN THE CITY OF RIO DE JANEIRO AND THE BCG VACCINE TEST IN PUBLIC SCHOOL STUDENTS (1933-1935)}

\begin{abstract}
The article highlights the major challenges of Primary Public Education in the city of Rio de Janeiro in the early 20th century, when it was the federal capital. In this period, debates involving physicians and professionals from various areas of society emerged around educational and health issues. The main sources used are: the magazine A Escola Primária and the report of the doctor Alvimar de Carvalho on the BCG vaccine test, both from the collection of the National Library. As a theoretical contribution, the possibilities opened by the new political history (RÉMOND, 2003) and the aid of microscopic observation (GINZBURG, 1990) are used to restore characters and processes through the clues left by historical subjects. The findings of the study show the importance of the use of varied sources and methods in the rescue of
\end{abstract}

\footnotetext{
${ }^{1}$ Doutora em Educação pela Universidade Federal do Rio de Janeiro, Brasil. Contato: marizagoliva@gmail.com.
} 
the history of school institutions and their intercession with political and social history.

Keywords: Tuberculosis, Primary Public Education of Rio de Janeiro, Alvimar de Carvalho, Instituto Ferreira Vianna, "The Primary School" Magazine.

\section{Introdução}

A História, cujo objeto precípuo é observar as mudanças que afetam a sociedade, e que tem por missão propor explicações para elas, não escapa ela própria à mudança. (RÉMOND, 2003).

A historiografia esteve preocupada por muito tempo em registrar grandes eventos e personagens, demarcando um espaço de interesses políticos onde predominava a história dos "de cima", como alerta Thompson (1998), ou das grandes estruturas sociais e econômicas. Porém, nos últimos vinte anos, vêm ocorrendo a transferência da história socioeconômica para a sociocultural e a redescoberta da história política e da narrativa (BURKE, 2010). Surge uma Nova História.

Foi decisiva a contribuição dos Annales nessa transição. A revista foi fundada para promover uma nova espécie de história e continua ainda hoje a encorajar inovações (BURKE, 2010, p. 12): promovendo a substituição da tradicional narrativa de acontecimentos por uma história-problema; privilegiando a história de todas as atividades humanas (uma "história total") e não apenas a história política; buscando a colaboração com outras disciplinas, tais como a Geografia, a Sociologia, a Psicologia, a Economia, a Linguística e a Antropologia Social.

A História Política deve muito às trocas com outras disciplinas como a Sociologia, o Direito Público, a Psicologia Social, a Psicanálise, a Linguística, a Matemática, a Informática, a Cartografia, entre outras. Os procedimentos estatísticos tendem a evoluir nas demonstrações de correlações

\footnotetext{
2 Parte das reflexões e análises apresentadas neste artigo, foram desenvolvidas na pesquisa de doutorado em Educação da autora: "Debates e embates na Instrução Pública Primária e seus efeitos sobre as práticas do Instituto Ferreira Vianna (Rio de Janeiro, 1929-1940)" (UFRJ/2015).
} 
com o auxílio da Matemática; a Linguística orientou a pesquisa para a análise do discurso; a Psicologia Social possibilita estudos para inscrever os comportamentos políticos na perspectiva mais ampla da prática social. Enfim, a questão da temporalidade na Nova História Política não faz mais “a felicidade dos calendários”, nas palavras de Rémond; não é mais a história do efêmero e do instante, mas agora conjuga a longa, a média e a curta duração (2003, p. 34-35).

Conectada à Nova História, à História das Mentalidades e à Nova História Cultural, surge a micro-história como uma iniciativa editorial na Itália, que incorporou o chamado "fatiamento" da história. O método apresentou uma preocupação problematizadora mais clara do objeto de investigações e dos seus vínculos sociais e trouxe como inovação o desenvolvimento da concepção de que o historiador, no processo de construção da realidade histórica, opera de forma indireta, buscando pistas, indícios e sinais deixados pelos homens. Dessa maneira é possível ao historiador restaurar personagens e processos através de indícios, de conjecturas e de efeitos, como afirma um dos maiores praticantes da micro-história, Carlo Ginzburg: "Quando as causas não são reproduzíveis, só resta inferi-las a partir dos efeitos" (1990, p. 169).

Observa Revel (2010), ao se referir ao pioneiro micro-historiador italiano Grendi, que "a história dominante tinha se mostrado incapaz de apreender tudo que se referia à experiência social; ... ou à "vivência"” (p. 438); por isto se faz a escolha por uma escala micro. "Reduzir o campo da análise significava, para Grendi, dar os meios de colocar em relação e, como esperava, de integrar as diferentes dimensões dessa experiência social”. (REVEL, 2010, p. 438).

Seguindo os mesmos conceitos, para Giovanni Levi (1992), a microhistória é essencialmente uma prática historiográfica em que suas referências teóricas são variadas e, de certa forma, ecléticas. O uso da noção de escala nesse método seria um procedimento analítico, aplicável a qualquer lugar, independentemente das dimensões do objeto estudado. $\mathrm{Na}$ dinâmica social, o que está em jogo na prática da micro-história "é a decisão de reduzir a escala de observação para propósitos experimentais. O princípio 
unificador de toda a pesquisa micro-histórica é a crença em que a observação microscópica revelará fatores previamente não observados" (LEVI, 1992, p. 139).

Na esteira da renovação historiográfica, este artigo tem a intenção de refletir sobre a história da tuberculose na cidade do Rio de Janeiro na década de 1930, doença que foi a causa-mortis da maior parte dos pais dos internos de diversas instituições escolares de acolhimento a menores órfãos e pobres. O estudo é parte das investigações empreendidas pela autora em sua tese de Doutorado em Educação, ao resgatar a história do Instituto Ferreira Vianna, que na década de 1930 abrigava cerca de 300 meninos órfãos e pobres, entre 6 e 12 anos, na então capital federal. Na pesquisa, a autora utilizou uma variedade de fontes, a fim de compreender como aqueles sujeitos históricos (políticos, diretores, inspetoras de disciplina, professores, alunos) agiram em determinadas situações, buscando conhecer e problematizar as suas práticas e projetos. Porém, neste breve estudo, intenta-se aproximar a lente sobre a questão da Saúde Pública e seu entrelaçamento com a Educação nesse início de século.

Portanto este artigo trará inicialmente um panorama das dificuldades enfrentadas pela Instrução Pública Primária no início do século XX, que levaram os diretores da Instrução Pública Municipal do Rio de Janeiro a priorizar algumas metas em detrimento de outras. Alguns desses desafios foram o analfabetismo, as condições prediais e higiênicas das escolas, os métodos de ensino e as epidemias. Nessa etapa do estudo, em que emergem debates envolvendo médicos e profissionais de diversas áreas da sociedade, atraídos pelos princípios da Eugenia, são utilizados como principais fontes os artigos e as reportagens publicados em uma coleção de revistas destinadas aos professores primários do Distrito Federal, organizadas pelos inspetores escolares, denominada A Escola Primária,3 localizada no acervo de periódicos da Biblioteca Nacional.

3 A Escola Primária era uma Sociedade Anônima, estabelecida e com foro eleito na cidade do Rio de Janeiro, cujo capital social era de três mil contos de réis, divididos em ações de trinta mil réis. De acordo com seu Estatuto, o funcionamento da sociedade foi estabelecido por vinte anos, que poderia ser prorrogado por assembleia geral dos acionistas. Com exceção de Afrânio Peixoto e Francisco M. Vianna, todos os sócios eram ou foram Inspetores Escolares. O desenho da revista apresenta na primeira página de 
Por ser esse um período em que eram desenvolvidas pesquisas para a criação de vacinas que erradicassem as doenças que se proliferavam mais facilmente no clima tropical, num segundo momento este artigo analisará as medidas do poder público contra as doenças contagiosas, especialmente a tuberculose, através da obra de Bertolli Filho (2001): História Social da Tuberculose e do Tuberculoso: 1900-1950.

O relatório do médico Alvimar de Carvalho, apresentado em um congresso sobre tuberculose em 1936, também localizado na Biblioteca Nacional, é a fonte central analisada na terceira parte deste estudo. Esta fonte, muito cara às investigações da autora, contém dados relevantes sobre o grau de contágio da doença entre os alunos de algumas escolas públicas da cidade do Rio de Janeiro, onde a vacina BCG fora testada, dentre elas o internato que foi seu objeto nos estudos de doutorado. Espera-se, assim, que este estudo possa contribuir para fazer avançar as reflexões cruciais em torno dos vínculos históricos entre Saúde Pública e Educação.

\section{A Instrução Pública Primária da capital federal em debate}

Pensar a educação popular na cidade do Rio de Janeiro quando sede do governo, adquire um caráter particular. No início do século XX a cidade já havia passado por reformas estruturais, como a retirada do morro do Castelo, e sua paisagem se aproximava às das nações "mais civilizadas". Com a promessa de que reformaria a capital da República, o presidente Rodrigues Alves, eleito de 1902 a 1906, deu posse como prefeito da cidade ao engenheiro Pereira Passos; este, por sua vez, nomeou Oswaldo Cruz

todos os fascículos o Sumário e o Editorial, com um tema em destaque. Dentre os diversos colaboradores da revista, constam os nomes de Oscar Clark; Escragnolle Doria, Alfredo Balthazar da Silveira, Othello Reis, Jonathas Serrano, Anísio Teixeira, Fernando de Azevedo, principalmente pelos cargos que estes ocupavam. Alguns não são identificáveis porque usavam as iniciais ou um pseudônimo. A coleção apresenta uma riqueza de temas, tais como: reformas de ensino; higiene escolar; métodos renovados de ensino; orientações sobre o ensino de diversas disciplinas; discussões sobre o ensino profissional nas escolas primárias; dentre outros. (OLIVEIRA, 2015, p. 74). 
como sanitarista a fim de reformar o centro da cidade, onde se concentrava um grande número de moradias e postos de trabalho, o que agravava a crise sanitária e a proliferação de doenças como a malária, a febre amarela e a tuberculose. Visando a maior inserção do Brasil no mercado mundial, o governo empreendeu uma mudança radical neste perfil, além de facilitar o acesso ao porto. A conhecida "Reforma Pereira Passos" atingiu seus objetivos, porém não erradicou a crise sanitária e as epidemias; apenas as afastou das vistas dos estrangeiros. Elas permaneciam nos morros, nos casebres, nas zonas rurais e, também, nas brechas da cidade, emergindo nas instituições, sobretudo nas escolas, ao lado de outra "doença”, o analfabetismo.

Este último era um problema de difícil solução. Muitas variáveis o compunham, uma delas era a questão do espaço físico. Não havia prédios escolares para atender toda a população de crianças que deveria estar na escola. Muitos prédios eram alugados e, por falta de investimento dos proprietários, não possuíam salas em número suficiente, os corredores eram estreitos e faltavam sanitários.

O problema da extincção do analphabetismo é por demais complexo para que possa ser resolvido no curto espaço de tempo de seis annos. [...] Um seculo de emancipação politica não conseguiu afastar do Brasil tão deprimente vergonha! (MAGIOLLI, 1916)4.

Na citação à epígrafe de Arthur Magiolli, inspetor escolar do $10^{\circ}$ Distrito, seis anos seria pouco para resolver um problema tão complexo. 5 Muitas variáveis o compunham, as quais emergem na escrita dos inspetores escolares e colaboradores da revista A Escola Primária. O primeiro trabalho publicado pela Seção Municipal de Estatística em 1897 se limitava a "apreciar o movimento escolar", nas palavras de Mário A. Freire (1916, p. 47-48), comparando o número de escolas, matrículas e frequência nos anos 1897, 1898 e, dez anos depois, 1908. No relatório, Mário A.

4 MAGIOLLI, Arthur. O centenario da independencia do Brasil e o analphabetismo. $A$ Escola Primaria. Anno I, no 2, nov. 1916, p. 45-46.

5 Esse era o prazo para a comemoração do Centenário da Independência. 
Freire ${ }^{6}$ apresenta a evolução de matrículas e frequência, mas não o aumento de escolas. Das 250 escolas existentes, 96 eram subvencionadas ou subsidiadas, isto é, a Prefeitura pagava a escolas particulares certa quantia por aluno, para que essas cobrassem quantias módicas ou concedessem gratuidade a alunos provavelmente mais necessitados. Essa informação confirma a falta de espaço físico na rede pública. No ano de 1908 o número de alunos do curso noturno (985), destinado a adultos do sexo masculino, passa a ser incluído na estatística.7

Em um novo confronto de dados, Freire aponta o número de matriculados nos cursos primários do diurno e do noturno nos seis anos seguintes, bem como o número de escolas e docentes. Informa também que a partir de 1910 começaram a funcionar no Distrito Federal dois cursos de Jardim de Infância, com 509 alunos matriculados.

Quadro 1: Estatística do Ensino Primário no Distrito Federal (1910-1915)

\begin{tabular}{|l|c|c|c|c|c|c|}
\hline $\begin{array}{c}\text { Dados } \\
\text { Ano }\end{array}$ & $\mathbf{1 9 1 0}$ & $\mathbf{1 9 1 1}$ & $\mathbf{1 9 1 2}$ & $\mathbf{1 9 1 3}$ & $\mathbf{1 9 1 4}$ & $\mathbf{1 9 1 5}$ \\
\hline $\begin{array}{l}\text { Matrícula } \\
\text { Diurno }\end{array}$ & 42.825 & 45.216 & 46.662 & 51.102 & 57.125 & 71.808 \\
\hline $\begin{array}{l}\text { Matrícula } \\
\text { Noturno }\end{array}$ & 613 & 1.511 & 2.246 & 4.229 & 6.422 & 9.470 \\
\hline $\begin{array}{l}\text { Número } \\
\text { de Escolas }\end{array}$ & 308 & 342 & 340 & 379 & 386 & ??? \\
\hline $\begin{array}{l}\text { Número } \\
\text { de Docentes }\end{array}$ & 1.088 & 1.205 & 1.439 & 1.674 & 1.715 & ??? \\
\hline
\end{tabular}

FONTE: Quadro elaborado pela autora,

com base nos dados do artigo de Mario A. Freire (1916).

Seu levantamento evidencia um aumento exponencial de matrículas e uma tímida ampliação do número de escolas, das quais não se sabe quantas seriam subvencionadas. O percentual de frequência em todo esse período foi em média $58 \%$ no diurno e $40 \%$ no noturno, segundo dados informados pelo autor. Possivelmente a não obrigatoriedade da frequência

\footnotetext{
${ }^{6}$ Mario A. Freire era formado em Direito, foi senador da República em 1908 e prefeito do Distrito Federal (Rio de Janeiro) entre 1919 e 1920.

7 Ver em Oliveira (2015, p. 78) - Quadro 4.
} 
fosse uma alternativa providencial para a superlotação das salas de aula. Quanto ao ensino privado, não era possível obter dados com a mesma precisão, informa o ex-senador, pois se tinha somente a informação de que em 1912 existiam 247 escolas com 20.949 alunos matriculados, compreendendo todos os níveis de ensino, inclusive o superior.

Essas questões denotam o quanto o problema do analfabetismo, considerado uma "chaga nacional", dependia de outros fatores para ser solucionado. Um dos mais graves, foi a falta de capacidade em termos de espaço para atender aos segmentos que seriam prioridade, como já visto, o que gerava outro debate: a gratuidade do ensino. Frota Pessoa traz uma importante informação no editorial da revista em maio de 1918: naquele ano foram dispendidos 10.500 contos somente com a Instrução Primária, destes 1.100 apenas com aluguéis de prédios, e 1.700 contos aplicados no Ensino Profissional. O autor avaliou em 200.000 o número de crianças em idade escolar; o que lhe levou a supor que se todas essas crianças "afluíssem” às escolas na mesma proporção das despesas, o orçamento municipal seria todo absorvido só com o Ensino Primário. Por essa razão, ele não se colocava ao lado dos defensores do ensino obrigatório.

A questão da obrigatoriedade escolar veio à tona em alguns momentos do debate na década de 1920, mas perdeu força porque para alguns era um contrassenso tornar obrigatório o ensino; visto que, nas circunstâncias vigentes, a Prefeitura não podia oferecer lugar a todos os que procuravam suas escolas. A administração seria forçada a multiplicar as escolas e os professores, sem ter condições. ${ }^{8}$ Tanto à obrigatoriedade dos pais, já inscrita na legislação estadual, quanto à obrigatoriedade do Poder Público, a obrigatoriedade escolar se fazia presente de forma muito débil nos debates, na opinião de Horta (1998, p. 16), não encontrando lugar na legislação federal antes de 1930. A obrigatoriedade do ensino primário só foi regulamentada por lei a partir da Constituição de 1934, sendo que já havia um século que sua aplicabilidade estava em discussão. Mesmo assim continuou sendo uma questão ambígua e contraditória. 9

\footnotetext{
${ }^{8}$ A reforma do ensino. [editorial]. A Escola Primaria. Anno XI, no 9 e 10, nov./dez. 1927.

9 Ler mais sobre Obrigatoriedade do ensino em Almeida (2012).
} 
Outra questão que deveria ser atacada com muito empenho pela $\mathrm{Mu}$ nicipalidade a fim de aniquilar o analfabetismo - e que muito interessa a este estudo - é a higiene nas escolas municipais da época, o que não envolvia somente a limpeza do ambiente, mas a formação de hábitos nas crianças e consequentemente nas famílias, assim como as precauções alimentares e a vacinação. Essa questão se interligava às anteriores, pois o fato de os alunos se aglomerarem nas salas de aula por falta de espaço físico trazia grande preocupação aos médicos escolares. Como se observa em longo artigo publicado no Jornal do Commercio, em 30 de agosto de 1916, pelo dr. Octavio Ayres, em que denuncia as péssimas instalações de grande número de escolas: problema que as gestões anteriores justificavam como decorrente da falta de recursos, dizia o comentarista do artigo; e o fato dos imóveis serem alugados de particulares que não faziam melhorias, resultava no número insuficiente de privadas. ${ }^{10}$

Buscando compreender os desníveis entre pobres e ricos que frequentavam a escola pública e criar alternativas de desenvolvimento para o país, o pensamento eugenista chega ao Brasil:

\begin{abstract}
Nas vossas escolas, onde recebeis o rico e o pobre, sentis a todo momento o vallo que separa um do outro e esta em vossas consciências que nao se organizara a nossa democracia, pondo-os no mesmo cadinho, dando-lhes a mesma educação. Isto é nosso grande problema social, o problema previo que havemos de resolver, e um problema de nivelamento - esteio e base da doutrina democrática. É preciso dar ao rico mais aptidão pratica e menos cultura abstracta e ao pobre, alem da educação, fornecer todas as cousas essenciaes - pois que todas lhe faltam - e que constituem as condições primarias da existência; o alimento, a hygiene, a vida social; a alegria... (PESSOA, 1929, p. 244-247). ${ }^{11}$
\end{abstract}

O pensamento de Frota Pessoa ${ }^{12}$ se une ao debate que se travou no final dos anos 1920, chegando ao Rio de Janeiro por influência da Socie-

${ }^{10} \mathrm{O}$ problema da hygiene nas escolas municipaes. A Escola Primaria. Anno I, $\mathrm{n}^{\mathrm{o}}{ }_{1}$, out. 1916, p. 4-5.

${ }^{11}$ Fonte: Revista A Escola Primária. Mantida a grafia da época.

12 José Getúlio da Frota Pessoa (1875-1951) bacharelou-se em Ciências Jurídicas e Sociais em 1904; foi jornalista e redator de diversos jornais do Rio de Janeiro; no jornal 
dade Eugênica de São Paulo. Essa instituição, formada por cientistas e intelectuais brasileiros, considerava-se uma associação científica de estudos e propaganda sobre a regeneração racial da população brasileira.

Em 1929, com o objetivo de comemorar o primeiro centenário da Academia Nacional de Medicina, foi realizado no Rio de Janeiro o I Congresso Brasileiro de Eugenia, que representou um dos principais eventos do meio médico e intelectual brasileiro ocorrido nessa década. Nesse mesmo ano o médico e farmacêutico eugenista Renato Kehl (1889-1974) publicou diversos trabalhos sobre Eugenia e fundou o Boletim de Eugenia a fim de fomentar o debate. Os primeiros passos do movimento no Brasil se confundiam com as ideias sanitárias, tendo como ponto de partida de estudos as questões relativas à influência do meio sobre a saúde e a raça nacional (SOUZA, 2005).

Foi instalado um novo cenário político e ideológico com a Revolução de 1930, que ajudou a expandir o espaço político e intelectual para a propaganda eugênica. Dessa forma, ao utilizar como retórica um discurso extremamente nacionalista, o movimento procurou associar a Eugenia à política nacional, conforme esclarece Souza (2005, p. 6), e “criar crianças eugênicas representaria [formar] uma população não degenerada no futuro, com plenas condições de se constituir em força de trabalho" (NASCIMENTO; FERREIRA, 2013, p. 323). Apesar de possuir uma série de ambiguidades, a Eugenia se transformou num discurso corrente e amplamente legitimado no meio científico, político e social brasileiro; os médicos e "homens do Estado" acreditavam contribuir para "melhorar a raça", obedecendo às suas leis.

O dr. Oscar Clark, médico inspetor escolar da $12^{\mathrm{a}}$. Circunscrição, por defender a medicina preventiva e o trabalho conjunto dos médicos nas escolas, teve grande participação nessas discussões. O seu primeiro artigo para a revista $A$ Escola Primária, em janeiro de 1917, relata que o Serviço

do Brasil, entre 1933 e 1944 publicou mais de 2.000 artigos sobre temas e problemas relacionados à educação brasileira. Trabalhou na Diretoria de Instrução Pública da Prefeitura do Rio de Janeiro chegando a secretário geral em 1922, e a subdiretor administrativo da Instrução na gestão de Fernando de Azevedo até 1932. (FÁVERO; BRITTO, 2002, p. 624). 
de Inspeção Médica das Escolas Municipais havia sido criado menos de seis meses antes e, diante das acusações do trabalho da inspeção médica ser mais estatístico que prático, explica que a finalidade essencial desse serviço era descobrir quais alunos necessitavam de tratamento médico e dentário; registrar os casos, organizar estatísticas e enviar as crianças para as Clínicas Escolares para receberem a assistência necessária. A Inspeção Médica seria apenas um serviço de iniciação da higiene escolar, mas, para prestar assistência à infância das escolas municipais, seria necessário criar um corpo de enfermeiros e construir as clínicas. Para viabilizar sua rápida construção e funcionamento, Oscar Clark sugeria que tivessem instalações modestas, que o tratamento fosse ministrado pelas enfermeiras e que apenas as crianças indigentes recebessem tratamento para os males descobertos pela inspeção médica. ${ }^{13}$

Afrânio Peixoto ${ }^{14}$ também se insere no debate sobre a higiene das escolas municipais. Por sua trajetória no campo da Medicina Legal e da Higiene, Peixoto publica no editorial da revista de maio de 1917 o "Programa Herbatiano da Educação pela Instrução", que consistia em ações que deveriam ser praticadas e exigidas pela escola e não somente ensinadas teoricamente como uma disciplina. De acordo com o programa, deveriam ser destinados antes do início das aulas dez minutos todas as manhãs a uma "vista de asseio", que a seu ver seria o maior benefício para a vida, dado por mestres e inspetores. ${ }^{15}$ Em outro artigo, Peixoto defende a tese de que

\footnotetext{
13 CLARK, Oscar. Tratamento médico escolar. A Escola Primaria. Anno I, nº 4, jan. 1917, p. 110-112.

14 Afrânio Peixoto (1876-1947) diplomou-se médico na Bahia e mudou-se para o Rio de Janeiro em 1902, sendo eleito para a Academia Brasileira de Letras em 1910. A porta de entrada de Peixoto para o mundo das letras deu-se através de sua aproximação do mercado editorial; "ser médico e literato era a questão", conforme expressão de Maio (1994). Em 1915 o médico e parlamentar Azevedo Sodré, ao assumir a direção da Diretoria de Instrução Pública do Distrito Federal, convidou-o para a direção da Escola Normal. Em 1916 tornou-se professor catedrático de Higiene da Faculdade de Medicina e foi elevado ao cargo de diretor geral da Instrução Pública do Distrito Federal, dentre outros cargos que assumiu posteriormente. Sobre a análise da produção de Afrânio Peixoto, ler Gondra e Silva (2011).

15 PEIXOTO, Afrânio. Programa herbartiano da educação pela instrução. A Escola Primaria. Anno I, no 8, maio de 1917.
} 
as doenças do Brasil não tinham relação com o clima, mas com o saneamento, e refutava a tese europeia afirmando: "Os europeus nos mandaram dizer que o clima seria o responsável [pelas doenças], porque só o clima da Europa é capaz de civilização...”; e acrescentava que o Saneamento deveria vir pela Educação: "Saneamento sim; educação também, porque será mais fácil e durável o saneamento"!16

Os inspetores e médicos estavam convencidos de que a escola pública era o único meio apto para as grandes campanhas populares e de que caberia aos professores servirem como elo nas campanhas de vacinação. Desse modo eram convocados a colocar a sua capacidade de persuasão e prestígio junto aos alunos e às famílias, a serviço da defesa antivariólica, sendo esta considerada uma obra humanitária altamente patriótica ${ }^{17}$.

Em 1925 é registrado grande surto epidêmico da varíola, sendo lembrado aos professores o dever de manter sempre viva a campanha "santa" pela vacinação sistemática. A professora primária também teria grande participação no Programa de Formação de Enfermeiras Visitadoras das Escolas Municipais, criado pelo médico inspetor Oscar Clark. Orientadas pelos médicos escolares, as futuras visitadoras deveriam ser selecionadas nas próprias escolas municipais, onde as professoras prestariam informações preciosas sobre o caráter, a inteligência e o "coração" das candidatas, como também se tornarem diretamente responsáveis pelo procedimento das moças nomeadas, em caráter não vitalício, sob sua indicação. Estas fariam parte do corpo de Serviço de Higiene Escolar, ao lado dos médicos inspetores e dos especialistas. Da mesma forma que as professoras, as enfermeiras deveriam ser pessoas que agradassem e conquistassem à primeira vista, mas também que tivessem "energia sufficiente para exercer autoridade sobre as classes pobres" (CLARK, 1923, p. 39). ${ }^{18}$

\footnotetext{
16 PEIXOTO, Afrânio. Educação e saneamento. [editorial]. A Escola Primaria. Anno II, $\mathrm{n}^{\circ} 12$, set. 1918.

17 A escola e a saúde. A Escola Primaria. Anno IX, nº 6, ago. 1925, p. 149.

18 CLARK, Oscar. As enfermeiras das Escolas Municipaes. A Escola Primaria. Anno VII, no 2, mar. 1923, p. 36-39.
} 


\section{Medidas públicas contra a tuberculose - o papel fundamental da Liga Brasileira Contra a Tuberculose}

“A tuberculose e a vacinação B.C.G.”, título da conferência proferida pelo professor João Marinho, no Rotary Club em 1935, ${ }^{19}$ apresenta uma alarmante situação na Saúde Pública da capital federal: nos anos de 1932, 1933 e 1934 morreram de tuberculose cerca de 5.000 pessoas por ano; o que significou que a cada duas horas morria uma pessoa vitimada pela doença, o que o levava a crer que a doença elevaria esse número a "um batalhão anônimo" andando pelas ruas.

A tuberculose foi definida desde o século passado como uma "moléstia social", da mesma forma que o eram a sífilis e o alcoolismo, os quais consistiram nos maiores desafios da ordem social. ${ }^{20}$ Em sua explanação, o professor João Marinho relembra que a Liga Brasileira Contra a Tubercu$\operatorname{lose}^{21}$ esteve à frente de todas as iniciativas de combate à doença: a propaganda higiênica, os sanatórios, os dispensários e ultimamente a vacinação B.C.G. Segundo ele, a instituição fundada em 1900, obteve as primeiras leis municipais de notificação compulsória, de desinfecção e de proibição de doentes escarrarem por toda a parte; fundou o seu primeiro dispensário em 1902, o Dispensário Azevedo Lima em 1907, e o Dispensário Viscondessa de Moraes em 1910. Porém, sua maior realização, foi a instituição da vacinação B.C.G., considerada pelo conferencista como o meio mais seguro, mais simples e o mais econômico na luta contra a tuberculose.

19 MARINHO, João. A tuberculose e a vacinação BCG. A Escola Primaria. Anno XIX, $\mathrm{n}^{\mathrm{o}}$ 2, maio 1935, p. 34- 37 .

20 BERTOLLI FILHO, Claudio. História Social da Tuberculose e do Tuberculoso: 1900-1950. Rio de Janeiro: Editora FIOCRUZ, 2001. Disponível em: http://static.scielo.org/scielobooks/4/pdf/bertolli9788575412886.pdf. O autor traça a história da origem milenar da tuberculose, discute o contexto mundial contemporâneo em que diversas tentativas são feitas a fim de se descobrir o seu antídoto, evidencia no Brasil as omissões do governo Vargas, e apresenta as iniciativas das grandes capitais: São Paulo e Rio de Janeiro. Na literatura, traz a representação da doença; revela casos pessoais de quem conviveu com a doença, valorizando a voz dos "sem voz na história".

${ }^{21}$ Ler sobre a organização e finalidade da Liga Brasileira Contra a Tuberculose em Câmara (2014). 
Os sanatórios, hospitais onde eram segregados e tratados os pacientes tuberculosos, eram considerados muito dispendiosos e deficientes devido às condições precárias e à segregação oferecida; na sua opinião, vistos com preconceito e tabu pela sociedade. Já os dispensários, criados pela Liga, propunham-se a "segregar os contagiantes e vigiar os predispostos" nas palavras do professor Marinho (1935, p. 36).22 Em tom de denúncia, o professor critica a falta de solução para o problema por parte do poder público: "a política". Finalizando, a fim de convencer das vantagens da vacina B.C.G., lembra que em 1907 a varíola matou no Distrito Federal 10.000 pessoas, e que graças à vacinação sistematizada, não houve mais óbitos de varíola.

Em termos nacionais, Bertolli Filho (2001, p. 100), esclarece que:

No Brasil, o acompanhamento das tendências internacionais na reorganização dos serviços de Higiene Pública ocorrida após o advento da República estabeleceu como obrigação exclusiva do diretor do Instituto Sanitário Federal a tarefa orientadora da população, limitando este compromisso às quadras definidas pelas crises epidêmicas. Foi somente no ano de 1921, por meio de uma nova reforma do setor saúde, que o país passou a contar com um órgão denominado Serviço de Educação e Propaganda Sanitária, encarregado de elaborar material didático destinado a instruir os cidadãos sobre os meios de evitar as pequenas e as grandes patologias que assolavam as áreas de concentração humana. Consultas aos arquivos desta repartição demonstram que ela cumpriu acanhadamente seus objetivos, pelo menos no transcorrer da primeira década de funcionamento. Isso porque o Serviço de Educação e Propaganda Sanitária restringiu-se quase que exclusivamente a traduzir e editar as mensagens elaboradas no exterior, sem ao menos tentar adaptá-las à problemática brasileira, repetindo os folhetos preparados pela Comissão Rockefeller e pela Cruz Vermelha e distribuídos na Europa a partir do ano de 1919.

A partir de 1920, o emprego do Raio X pela medicina inaugurou novos recursos para a averiguação clínica da pessoa infectada pela tuberculose, tornando-se comum o seu uso; porém, era pouco, tendo em vista a

${ }^{22}$ Outra iniciativa da Liga, segundo Câmara (2014), foi a criação de 2 Preventórios do tipo marítimo, com o objetivo de prevenir, fortalecer e educar higienicamente as crianças. 
necessidade de conter o contágio em alta escala. Durante o governo Vargas, as verbas federais destinadas à higiene coletiva eram reduzidas, visto que eram aplicadas quase exclusivamente na melhoria das condições sanitárias da capital da República. Portanto ficava a cargo de cada estado a responsabilidade pela criação de fundos próprios para tratamento dos enfermos pobres e a criação de mecanismos de contenção da doença, pelo menos até 1938; o que ocasionou, no transcorrer da década de 1930, demonstrações de descontentamento por parte dos médicos, principalmente os de São Paulo. ${ }^{23}$ Existiam poucas entidades direcionadas ao tratamento das vítimas do bacilo em 1936, sendo o estado de São Paulo o que concentrava o maior número de unidades de saúde, contando com 14 sanatórios e hospitais-sanatórios; Minas Gerais possuía 3 sanatórios, o estado do Rio de Janeiro 2 nosocômios e o Paraná apenas uma casa de saúde especializada (BERTOLLI FILHO, 2001, p. 69-70).

Em termos de políticas públicas, somente a partir de 1938 a administração varguista mostrou-se disposta a elaborar um projeto federal de assistência aos doentes pobres, impulsionada pela situação vexatória causada pelo relatório de um médico higienista norte americano, o qual tecia comparações entre os Estados Unidos e a América Latina. Segundo o médico, a América Latina era vitimada por um conjunto de doenças contagiosas, sendo a tuberculose a patologia que mais ceifava vidas (BERTOLLI FILHO, 2001). A partir daí o projeto do governo impulsionou as campanhas contra a doença, mostrando-se sensível aos pedidos de apoio da Federação Brasileira Contra a Tuberculose e também oferecendo suporte econômico aos sucessivos Congressos Nacionais de Tuberculose realizados a partir do final dos anos 1930.

${ }^{23}$ A Revista Paulista de Tisiologia ocupou a posição de porta-voz privilegiada dos interesses e dos dilemas que pontuavam as ações dos profissionais dedicados à luta contra a Tuberculose. "O empenho da Revista em expor o descontentamento dos médicos em relação ao Estado varguista frutificou, mas também permitiu que clareassem os antagonismos doutrinários e os interesses institucionais divergentes que impregnavam os debates sobre a Peste Branca” (BERTOLLI FILHO, 2001, p. 84). 


\section{O teste da vacina BCG e o} relatório do dr. Alvimar de Carvalho²4

A fim de inibir a proliferação da tuberculose, em 1934 foi firmado acordo entre o Departamento de Educação da Prefeitura do Distrito Federal e o Serviço BCG da Liga Brasileira Contra a Tuberculose para ser administrada a vacina BCG a 100 escolares da prefeitura durante o referido ano, pois essa já figurava como uma das doenças que mais fazia crescer o número de crianças órfãs no Distrito Federal. O Instituto Ferreira Vianna, ${ }^{25}$ instituição educacional criada no contexto dos debates sobre a abolição da escravidão e a educação da infância pobre, pôde sentir no seu cotidiano os efeitos das medidas sanitárias nos anos 1930, através de campanhas contra a doença, pois foi uma das escolas que serviram de laboratório para o teste da BCG por via oral, sob a responsabilidade do dr. Alvimar de Carvalho. Um artigo sobre essa experiência foi apresentado em um congresso sobre tuberculose, o qual na introdução caracteriza os alunos ali internados e as circunstâncias em que morreram seus pais:

INFECÇÃO TUBERCULOSA NO INSTITUTO FERREIRA VIANNA EM 1934 - Este Instituto, abriga escolares de idade variando entre 7 e 14 anos. A maioria dos escolares, de condição social pobre, era orphã, ou de pae, ou de mãe, ou de ambos, sendo a "causa-mortis" dos progenitores occasionada pelas doenças communs á idade adulta (esclerose cardio renal, tuberculose, câncer, etc.). Em agosto e setembro de 1934, estudamos a infecção tuberculosa em 316 escolares. Pelo emprego, seriado, de duas

\footnotetext{
24 Não foi possível para este estudo localizar uma biografia do dr. Alvimar de Carvalho, porém se descobriu que há um posto de saúde em Pedra de Guaratiba (Rio de Janeiro/RJ) com o seu nome.

25 O Instituto Ferreira Vianna, hoje Escola Técnica Estadual Ferreira Vianna, da Fundação de Apoio à Escola Técnica (FAETEC/RJ), tem origem como instituição no final do século XIX, sob a denominação de Casa de São José (1888) sob a direção das irmãs de caridade. Sua finalidade era abrigar crianças abandonadas na idade de 6 a 12 anos, do sexo masculino, órfãs e com risco de se tornarem desviantes na sociedade. No período de 2010 a 2015 a autora deste artigo desenvolveu pesquisa documental no seu acervo, através do grupo de estudos: "Centro de Memória Ferreira Vianna: documentação, ensino e infância trabalhadora (1888-1942)”, sob a coordenação da prof. Dra. Irma Rizzini (PPGE/UFRJ). A escola localiza-se no bairro da Tijuca, no Rio de Janeiro/RJ.
} 
cuti-reações e de duas intradermo-reações (1/200 e 1/20), encontramos um índice de infecção tuberculosa bem elevado. Assim, de um total de 316 meninos, 234 ou seja 74\%, eram de tuberculino-positivos. $O$ índice de infecção subia progressivamente com as idades: assim, era de 63,6\% entre 7 e 9 annos, de $76,1 \%$ entre 9 e 13 annos e 77,1\% entre 13 e 14 annos. Somente 82 escolares, ou seja $26 \%$, eram de tuberculino-negativos, isto é, não infectados por bacilos tuberculosos. ${ }^{26}$

Segundo a orientação dos técnicos, nesse teste, qualquer indivíduo de qualquer idade poderia ser vacinado, desde que fosse "tuberculino-negativo”. Entre os 82 escolares tuberculino-negativos do Instituto Ferreira Vianna, 69 foram vacinados com BCG por via oral; segundo o médico, nada ocorreu de anormal após a vacinação. Passadas 6 a 8 semanas, estes foram examinados alergicamente e foi constatado que a vacina "pegou" em 39 - um percentual de 56,5\%. Decorridos 9 a 10 meses após a vacinação, a alergia foi pesquisada em 60 desses escolares, porque 9 haviam sido transferidos para o Instituto João Alfredo. ${ }^{27} \mathrm{O}$ médico faz questão de acentuar, em seu relatório de 12 páginas, que os escolares continuaram a viver nas mesmas condições que viviam antes da vacinação, não sendo aconselhada nenhuma nova medida higiênica e nenhum tratamento especial, com o intuito de provar sua eficácia.

Ao final, o relatório ressalta o alto índice de infecção tuberculosa dos escolares no Distrito Federal, pois tanto no Instituto Ferreira Vianna (meninos de 7 a 14 anos) quanto no Instituto Orsina da Fonseca (meninas de 8 a 18 anos), ${ }^{28}$ como também no ambulatório da Liga Brasileira contra a Tuberculose, a infecção tuberculosa era em torno de 70\% na faixa etária de 10 a 15 anos.

Por fim, relata que sua experiência tentou provar que os malefícios da infecção tuberculosa "tão espalhada" poderiam ser substancialmente reduzidos pela vacinação com BCG via oral. Segundo Bertolli Filho (2001),

${ }^{26}$ CARVALHO, Alvimar de. A vacinação com B.C.G., por via oral, em escolares do Instituto Ferreira Vianna, da Prefeitura do Districto Federal. Separata da Revista Tuberculose, Tomo III, fev. 1936. Biblioteca Nacional - obras gerais.

${ }_{27}$ Para o Instituto João Alfredo eram transferidos os meninos que atingiam 13 anos, a fim de continuarem sua formação profissional em regime de internato.

${ }^{28}$ Sobre a história do Instituto Orsina da Fonseca, instituição de ensino profissional feminino, ver Câmara (2013). 
depois de estabelecida a infecção inicial provocada pelo bacilo de Koch, a continuidade da chamada Peste Branca permanece incerta; ela pode evoluir para uma tuberculose crônica ou para a tísica progressiva aguda. "A infecção, contudo, pode permanecer estacionária, abrindo chances para que os bacilos latentes reiniciem sua ação destrutiva anos após o evento inicial” (BERTOLLI FILHO, 2001, p. 30).

A vacina BCG, que possui essa sigla por ser um Bacilo Biliado preparado pelos franceses Calmette e Guérin, foi obtida experimentalmente em 1906 e inoculada em crianças e adolescentes a partir da década de 1920. É uma solução preventiva e não curativa, composta de bacilos atenuados de tuberculose bovina. Nesse período, a vacina foi testada em 272 crianças da cidade de Lübeck na Alemanha, provocando um terrível acidente, que resultou na morte ou infecção de pelo menos metade dessas crianças. Essa fatalidade ocorreu, segundo relatórios de Calmette e Bernard, ${ }^{29}$ por não estarem convenientemente atenuadas as culturas microbianas. Em consequência, teve início uma campanha mundial contra a BCG, e o emprego disseminado da vacina apenas se deu alguns anos depois, com as devidas precauções, como se pôde observar no caso dos internos do Instituto Ferreira Vianna, do Instituto Orsina da Fonseca e das crianças do ambulatório da Liga Brasileira Contra a Tuberculose na cidade do Rio de Janeiro.

\section{Considerações finais}

Clarice Nunes e Marta Carvalho (2005), ao apontarem e aprofundarem a relação entre historiografia da educação e fontes, demarcam a importância da problematização e alargamento da concepção de fontes em história da educação, visando a construção de uma historiografia menos generalista e estereotipada, bem como a sua relação com a história cultural.

29 Apud Bertolli Filho (2001, p. 41-42). 
Advertem também as autoras, que "a reflexão sobre as fontes é ao mesmo tempo uma reflexão sobre os limites não só das práticas institucionais, no que diz respeito à localização, conservação e divulgação dos acervos, mas também das práticas discursivas no âmbito da história”. (NUNES; CARVALHO, 2005, p. 29-30).

Buscou-se compartilhar neste artigo as descobertas que a visita aos arquivos escolares e públicos podem proporcionar, no sentido de promover um deslocamento da narrativa dominante, cristalizada, aguçando dessa maneira a observação de fatores anteriormente não percebidos.

As descobertas realizadas pelo estudo empreendido traduzem a importância do uso de fontes e métodos variados no resgate da história das instituições escolares e sua intercessão com a história política e social. Dessa forma, espera-se que se tenha apontado caminhos para novas pesquisas e contribuído para a ampliação do debate histórico-educacional.

\section{Referências}

ALMEIDA, Cíntia Borges de. Entre a "tiramnya cruel" e a "pedra fundamental": a obrigatoriedade do ensino primário como uma técnica de governo em Minas Gerais. 2012. 275 f. Dissertação (Mestrado em Educação), PROPED/UERJ, Rio de Janeiro, 2012.

BERTOLLI FILHO, Cláudio. História Social da Tuberculose e do Tuberculoso: 1900-1950. Rio de Janeiro: Editora FIOCRUZ, 2001. Disponível em: http://static.scielo.org/scielobooks/4/pdf/bertolli9788575412886.pdf. Acesso em o5 dez. 2014.

BURKE, Peter. A escola dos Annales (1929-1989): a revolução francesa da historiografia. 2. Edição. São Paulo: Editora da Unesp, 2010.

CÂMARA, Sônia. Da esperança sutil à realidade forte: a Liga Brasileira Contra a Tuberculose e os projetos de assistência à infância nas décadas de 1920 a 1930. In: Anais do XVI Encontro Regional de História - ANPUH RIO: Saberes e Práticas Científicas. Rio de Janeiro, 2014.

. Reinventando a escola: o ensino profissional feminino na Reforma Fernando de Azevedo de 1927 a 1930. Rio de Janeiro: Quartet, Faperj, 2013. 
FÁVERO, Maria de Lourdes de Albuquerque; BRITTO, Jader de Medeiros (Orgs.). Dicionário de educadores no Brasil. $2^{\mathrm{a}}$. Edição ampl. Rio de Janeiro: Editora UFRJ, MEC-INEP-COMPED, 2002.

GINZBURG, Carlo. Mitos, emblemas, sinais: morfologia e história. Tradução: Frederico Carotti. São Paulo, SP: Companhia das Letras, 1990.

GONDRA, José; SILVA, José Cláudio S. Escritas da história - um estudo da produção de Afrânio Peixoto. In: História da Educação na América Latina: Ensinar \& Escrever. Rio de Janeiro: EdUERJ, 2011.

HORTA, José Silvério Baia. Direito à educação e obrigatoriedade escolar. Cadernos de Pesquisa, ${ }^{0}$ 104, jul. 1998, p. 5-34.

LEVI, Giovanni. Sobre micro-história. In: BURKE, Peter (Org.). A escrita da história: novas perspectivas. São Paulo: Ed. UNESP, 1992. p. 133-161. MAIO, Marcos Chor. Afrânio Peixoto: notas sobre uma trajetória médica. Revista da SBPC, no 11, p. 75-81, 1994.

NASCIMENTO, D. R.; FERREIRA, L. O. Da hereditariedade à pobreza: combate à tuberculose e ao bócio na infância em tempos de eugenia. In: MOTA, A.; MARINHO, G. S. M. (Org.) Eugenia e história: ciência, educação e regionalidades. São Paulo: USP, Faculdade de Medicina: UFABC, Universidade Federal do ABC: CD.G Casa de Soluções e Editora, 2013. p. 321-340.

NUNES, Clarice; CARVALHO, Marta. Historiografia da educação e fontes. In: GONDRA, José Gonçalves (Org.). Pesquisa em história da educação no Brasil. Rio de Janeiro: DP\&A, 2005. p. 17-62.

OLIVEIRA, Mariza da Gama Leite de. Debates e embates na instrução pública primária e seus efeitos nas práticas do Instituto Ferreira Vianna (Rio de Janeiro, 1929-1940). 2015. 378 f. Tese (Doutorado em Educação) - Faculdade de Educação, Universidade Federal do Rio de Janeiro (UFRJ), Rio de Janeiro, março de 2015.

RÉMOND, René. Uma história presente. In: (Org.). Por uma história política. 2. edição. Rio de Janeiro: FGV, 2003. p. 13-36.

REVEL, Jacques. Micro-história, macro-história: o que as variações de escala ajudam a pensar em um mundo globalizado. Revista Brasileira de Educação, v. 15, n. 45, p. 434-444, set./dez. 2010.

SOUZA, Vanderlei S. A eugenia no Brasil: ciência e pensamento social no movimento eugenista brasileiro do entre-guerras. In: Anais ANPUH XXIII Simpósio Nacional de História, 2005, Londrina. Disponível em: http://anpuh.org/anais/wp-content/uploads/mp/pdf/AN-

PUH.S23.1587.pdf. Acesso em: 31 jan. 2015.

THOMPSON, Edward P. Costumes em comum. São Paulo: Companhia das Letras, 1998. 


\section{Fontes}

A ESCOLA e a saúde. A Escola Primaria. Anno IX, nº 6, ago. 1925, p. 149. A REFORMA do ensino. [editorial]. A Escola Primaria. Anno XI, $\mathrm{n}^{0} 9$ e 10, nov./dez. 1927.

CARVALHO, Alvimar de. A vacinação com B.C.G., por via oral, em escolares do Instituto Ferreira Vianna, da Prefeitura do Districto Federal. Separata da Revista Tuberculose, Tomo III, fev. 1936. Biblioteca Nacional obras gerais.

CLARK, Oscar. As enfermeiras das Escolas Municipaes. A Escola Primaria. Anno VII, $\mathrm{n}^{\circ}$ 2, mar. 1923, p. 36-39.

CLARK, Oscar. Tratamento medico escolar. A Escola Primaria. Anno I, $\mathrm{n}^{\mathrm{o}}$ 4, jan. 1917, p. 110-112.

FREIRE, Mario A. O ensino primário. A Escola Primaria. Anno I, $\mathrm{n}^{\mathrm{0}}$ 1, 1916, p. 47-48.

MAGIOLLI, Arthur. O centenario da independencia do Brasil e o analphabetismo. A Escola Primaria. Anno I, no 2, nov. 1916, p. 45-46.

MARINHO, João. A tuberculose e a vacinação BCG. A Escola Primaria. Anno XIX, $\mathrm{n}^{0}$ 2, maio 1935. p. 34-37.

O PROBLEMA da hygiene nas escolas municipaes. [editorial]. A Escola Primaria. Anno I, no 1, out. 1916, p. 4-5.

PEIXOTO, Afrânio. Educação e saneamento. [editorial]. A Escola Primaria. Anno II, no 12 , set. 1918.

PEIXOTO, Afrânio. Programa herbartiano da educação pela instrução. $A$ Escola Primaria. Anno I, no 8, maio 1917.

PESSOA, Frota. A reforma do ensino primário - suas características fundamentaes (conferencia realizada no salão do instituto nacional de musica, pelo dr. Frota Pessoa e reproduzida em Bello - Horizonte). A Escola Primaria. Anno XII, no ${ }^{0}$ 11, jan. 1929, p. 244-247.

Recebido em 22 de novembro de 2016. Aprovado em 18 de dezembro de 2016. 